\title{
Analgesic Effects of Vilazodone, Indatraline, and Talsupram in a Rat Model of Neuropathic Pain
}

\author{
(D) Levent HACISÜLEYMAN*, (D) Bülent SARAÇ, (D) Ziad JOHA \\ Sivas Cumhuriyet University, Faculty of Medicine, Department of Pharmacology, Sivas, Türkiye
}

\begin{abstract}
Objectives: Drugs that inhibit the reuptake of serotonin, norepinephrine, and/or dopamine are widely used for treating depressive disorders and have emerged as effective drugs for neuropathic pain. They have no substantial anti-nociceptive effects but are considered, with gabapentin/ pregabalin, first-line drugs for neuropathic pain.

Materials and Methods: In this study, three different antidepressant agents were used in different doses to investigate their anti-hyperalgesic effects in rat models of neuropathic pain using hot plate and tail flick methods. They have different mechanisms of action; vilazodone hydrochloride is a selective serotonin inhibitor and a $5-\mathrm{HT}_{1 \mathrm{~A}}$ partial agonist; talsupram hydrochloride is a selective noradrenaline inhibitor, and it has a high affinity for noradrenaline transporter (NET), whereas indatraline hydrochloride is a triple reuptake inhibitor that inhibits transporters for 5-HT (SERT), dopamine (DAT), and NET.

Results: All the drugs used in the experiment were found to have an anti-hyperalgesic effect in both tests compared to the sham group. When antihyperalgesic effects of the three agents were compared to each other, it was found that talsupram hydrochloride was significantly more effective than the two other drugs in hot plate test. However, there was no statistically significant difference in the tail flick test. Indatraline hydrochloride was more effective than vilazodone hydrochloride at the same doses in the tail flick test.

Conclusion: Our data suggest that three drugs are effective analgesics in rat models of neuropathic pain and inhibition of noradrenaline reuptake represents the cornerstone of analgesic mechanisms of effective antidepressants.
\end{abstract}

Key words: Neuropathic pain, antidepressant, vilazodone, talsupram, indatraline, hot plate, tail flick, anti-hyperalgesic, sciatic nerve ligation

\section{INTRODUCTION}

The International Association for the Study of Pain defined neuropathic pain as "pain caused by a lesion or disease of the somatosensory nervous system". According to a report published in 2011, one-third of Americans experience chronic pain. This exceeds total amount of cardiovascular diseases, diabetes, and cancer cases. ${ }^{2}$ The prevalence rate of chronic pain in Europe is about 25-30\%. ${ }^{3}$ Almost one-fifth of people affected by chronic pain have neuropathic pain. 4,5 These high prevalence rates of chronic pain, especially neuropathic pain, are due to the lack of effective drugs. While nociceptive pain can be managed with analgesic drugs such as opioids and non-steroidal anti-inflammatory drugs, the medications used to manage neuropathic pain have a mild effect and in a small percentage of patients. This is mainly because they are unable to target the exact underlying mechanisms; this is why syndromes like fibromyalgia, whose pathophysiological mechanisms are not unclear, have lower treatment success rates. ${ }^{6}$ The existing medications for neuropathic pain are nonspecific and often inadequately effective. ${ }^{7}$ Other medications such as opioids, on the other hand, have serious side effects. Therefore, there is a persistent need for improved and more specific therapeutic strategies. Before clinicians can prescribe precise medications for neuropathic pain patients, main targets in the pathway must be understood.

The pharmacological treatment of neuropathic pain is complicated and there is no effective treatment for many patients. While a general consensus indicates as to which drugs should be used as first-line medications, controversy over second- and third-line drugs continues, particularly regarding weak and strong opioids. Although opioids are effective in the management of neuropathic pain, they are 
not prescribed as first-line drugs because of their adverse reactions and concerns about abuse and addiction. ${ }^{8}$

Antidepressants have been proven to have analgesic effects in chronic pain even though they were not initially designed to be used as analgesic drugs. Antidepressants have practically no antinociceptive effects, but are considered with pregabalin and gabapentin first choice drugs for neuropathic pain ${ }^{7,9-11}$ and fibromyalgia. ${ }^{12}$

There is no full understanding of how antidepressants are effective in pain management. An early concept of analgesic mechanisms of antidepressants for neuropathic pain was that these drugs could potentiate effectiveness of the descending noradrenergic and serotonergic inhibitory pathways that extend from the brain stem to the dorsal horn of the spinal cord. This is done by inhibiting the reuptake of serotonin and noradrenaline released into the spinal synapses between the first-order neurons (nociceptors) and the second-order neurons (spinothalamic neurons). The synaptic transmission between these neurons can be inhibited by the neurotransmitters released from the inhibitory descending fibers, such as noradrenaline, which binds $\alpha$-2 adrenergic receptors. They can also induce spinal interneurons to release inhibitory materials like GABA and endogenous opioids, such as serotonin at its metabotropic receptors or noradrenaline at $\alpha-1$ adrenergic receptors. ${ }^{13}$

Our study aimed to explore the anti-hyperalgesic effect of three different antidepressant drugs at different doses in rat models of neuropathic pain using hot plate and tail flick methods, and to compare analgesic activity of these drugs. Anti-hyperalgesic effects of these agents have not been studied extensively before.

\section{MATERIALS AND METHODS}

\section{Animals}

Experiments were performed on adult male Wistar albino rats weighing $200-225 \mathrm{~g}$. The animals were kept at $22 \pm 1^{\circ} \mathrm{C}$, four in each cage, and maintained with a light-dark cycle of 12: $12 \mathrm{~h}$ and free access to water and food. Sivas Cumhuriyet University Animal Ethics Committee approved all experiment protocols (approval no: 65202830-050.04.04-284).

\section{Drugs}

5-[4-[4-(5-Cyano-1H-indol-3-yl) butyl]-1-piperazinyl]2-benzofurancarboxamide hydrochloride (vilazodone hydrochloride) (BLDpharm), 1,3-dihydro-N,3,3-trimethyl1-phenylbenzo[c]thiophene-1-propanamine hydrochloride (talsupram hydrochloride) and (1R,3S)-rel-3-(3,4dichlorophenyl)-2,3-dihydro- $\mathrm{N}$-methyl-1H-inden-1-amine hydrochloride (indatraline hydrochloride) (Tocris Bioscience) were diluted in dimethyl sulfoxide. Solutions were freshly prepared on the days of experimentation. Intraperitoneal (I.P.) vilazodone hydrochloride (5-HT1A partial agonist and SSRI 2.5, 5, and $10 \mathrm{mg} / \mathrm{kg}$ ), talsupram hydrochloride (selective inhibitor of noradrenalin transporters $2.5,5$, and $10 \mathrm{mg} / \mathrm{kg}$ ), and indatraline hydrochloride (5-HT noradrenalin and dopamine reuptake inhibitor $2.5,5$, and $10 \mathrm{mg} / \mathrm{kg}$ ) were applied before the analgesia tests.

\section{The experimental protocol and the analgesia tests}

All experiments were carried out blindly between 10.00 and $16.00 \mathrm{~h}$ in normal light and temperature $\left(22 \pm 1^{\circ} \mathrm{C}\right)$ in a quiet room. The rats were allowed to adapt to the laboratory for at least $2 \mathrm{~h}$ before the test and their tails were marked to differentiate the treatment groups. The rats were randomized into 10 groups [3 groups for each drug (1 group for each dose) and 1 group as a sham]. Each experimental group had six rats. The same person performed all neuropathic operations and analgesia tests to minimize experimental variability.

\section{Surgical intervention}

The neuropathic pain model was produced by partial sciatic nerve ligation. Surgical interventions were performed at Sivas Cumhuriyet University Medical Faculty Experimental Animals Laboratory. Anesthesia was performed using intramuscular ketamine $(90 \mathrm{mg} / \mathrm{kg}$ ) and xylazine $(3 \mathrm{mg} / \mathrm{kg})$. Under aseptic conditions, a $1 \mathrm{~cm}$ incision was applied to biceps femoris and the sciatic nerve was reached in the middle thigh level of the right leg. Then, the sciatic nerve was freed of adherent tissues with careful blunt dissection and the dorsal one-third to half of the nerve was tightly ligated with 4.0 chromic catgut. The incision was closed with 4.0 silk. In sham group of rats, the same intervention was applied but without nerve ligation. After surgery, the rats were returned to their cages and kept for 21 days under the abovementioned same conditions. ${ }^{14,15}$

\section{Analgesia tests}

To evaluate thermal pain standard tail flick test (May TF 0703 Tail beat unit, Commat) and hot plate test (May AHP 0603 Analgesic HP, Commat) devices were used. In the tail flick test, an intensive light beam was aimed at the animal's tail and a timer begins. When the animal flicks its tail, the timer is stopped and recorded time (latency) represents the pain threshold. Tailflick latencies were measured before the administration of the vehicle or investigational drugs to obtain a baseline and 15, 30, 60,90 and 120 min after the I.P. administration. The maximum response time was set to 15 seconds (cut-off latency) to avoid tissue damage. Rats that did not show a response within 15 seconds were excluded. The hyperalgesic responses in this test reflect the mechanisms of pain in the central nervous system. ${ }^{16-18}$

A hot plate device was used to evaluate thermal pain. In this test, the rats were placed on a hot plate with the temperature set at $53 \pm 0.5^{\circ} \mathrm{C}$ for a maximum time of $30 \mathrm{~s}$ to prevent injury. Response time was recorded (when the animals licked their fore and hind paws or jumped) before and 15, 30, 60, 90, and 120 min after I.P. administration of the vehicle or test drugs. The hyperalgesic reactions in this test reflect the mechanisms of pain in both the central and peripheral nervous systems. ${ }^{16,18}$

\section{Statistical analysis}

In all groups for each rat, antinociceptive effects of the drugs were measured as tail flick and hot plate latencies and 
transformed into a percentage maximum possible effect ( $\%$ MPE). MPE was obtained using the formula: [MPE= (post-drug latency-pre-drug latency) / (cut-off latency-pre-drug latency) $\times$ 100]. Pre-drug and post-drug $N$ values were the same in each group. The data were analyzed using one and two-way analysis of variance (ANOVA) and repeated measures ANOVA followed by a Tukey post-hoc test (SPSS 14.0 for Windows) for multiple comparisons between groups. All data are presented as a mean \pm standard error of the mean. The significance level was determined as $p<0.05$.

\section{RESULTS}

Determination of neuropathic pain formation by sciatic nerve ligation

The occurrence of neuropathic pain in the rats was detected using the paired student's t-test. The post-surgery basal latencies of the rats were considerably lower than the presurgery basal latencies in both hot plate and tail flick tests $(p<0.05)$ (Figures 1 and 2).

\section{Effects of vilazodone hydrochloride on neuropathic pain}

Vilazodone hydrochloride was applied at three doses: 2.5, 5 , and $10 \mathrm{mg} / \mathrm{kg}$. In both tail flick and hot plate tests, the responses were measured before the drug was administered I.P. and after the administration at $15,30,60,90$, and 120

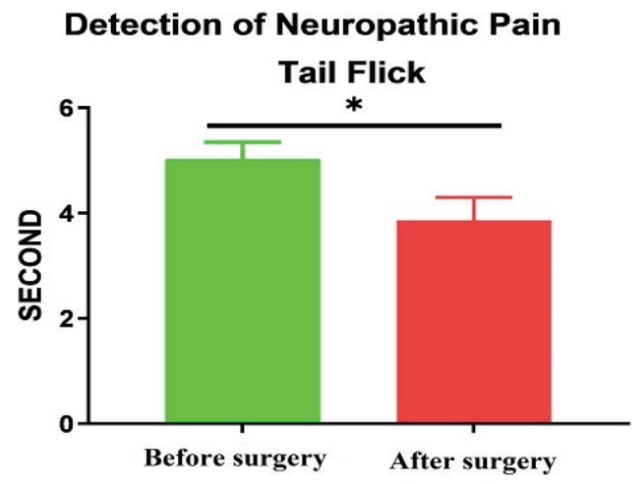

Figure 1. Tail flick basal latencies of rats before and after surgery ${ }^{*} p<0.05$ paired student's $t$-test)

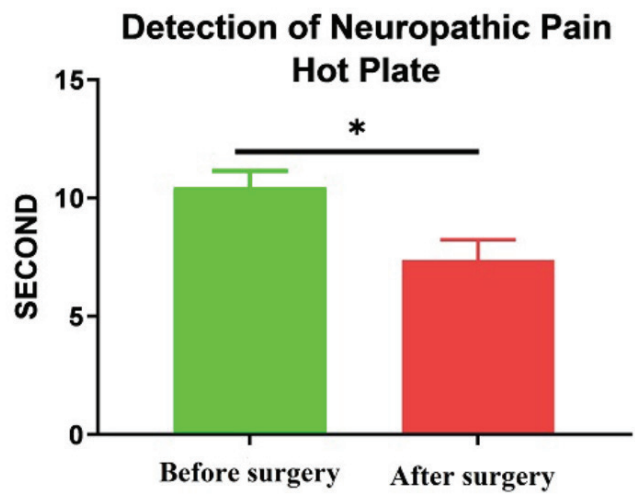

Figure 2. Hot plate basal latencies of rats before and after surgery ( ${ }^{*} p<0.05$ paired student's $t$-test) min. Maximum \% MPE was observed in 90 mins after administration of these three doses. One-way ANOVA test was applied to compare the different doses with the sham group and with each other. In both tail flick and hot plate tests, doses at 5 and $10 \mathrm{mg} / \mathrm{kg}$ were found to be effective against neuropathic pain compared with the sham group. Dose at 10 $\mathrm{mg} / \mathrm{kg}$ was effective from 30 to 120 mins in both tests with a statistically significant difference compared with $2.5 \mathrm{mg} /$ $\mathrm{kg}$ dose at $90 \mathrm{~min}$ in the hot plate test and in 90, $120 \mathrm{~min}$ in the tail flick test. Dose at $5 \mathrm{mg} / \mathrm{kg}$ was effective from 30 to $90 \mathrm{~min}$ in both tests. Dose at $2.5 \mathrm{mg} / \mathrm{kg}$ was not statistically different from the sham group in the hotplate test at all minute points, while it was noticed to be effective only in the tail flick test at 60 and 90 min (Figure 3).

\section{Effects of talsupram hydrochloride on neuropathic pain}

Talsupram hydrochloride was applied intraperitoneally at three doses: $2.5,5$, and $10 \mathrm{mg} / \mathrm{kg}$. The maximum percentage MPE was observed 60 min after the drug was administered for all three doses. One-way ANOVA test was used. The first dose of $2.5 \mathrm{mg} / \mathrm{kg}$ was effective from 30 to 120 mins in the hot plate test and from 30 to $90 \mathrm{~min}$ in the tail flick test. The other two doses at 5 and $10 \mathrm{mg} / \mathrm{kg}$ were effective at all
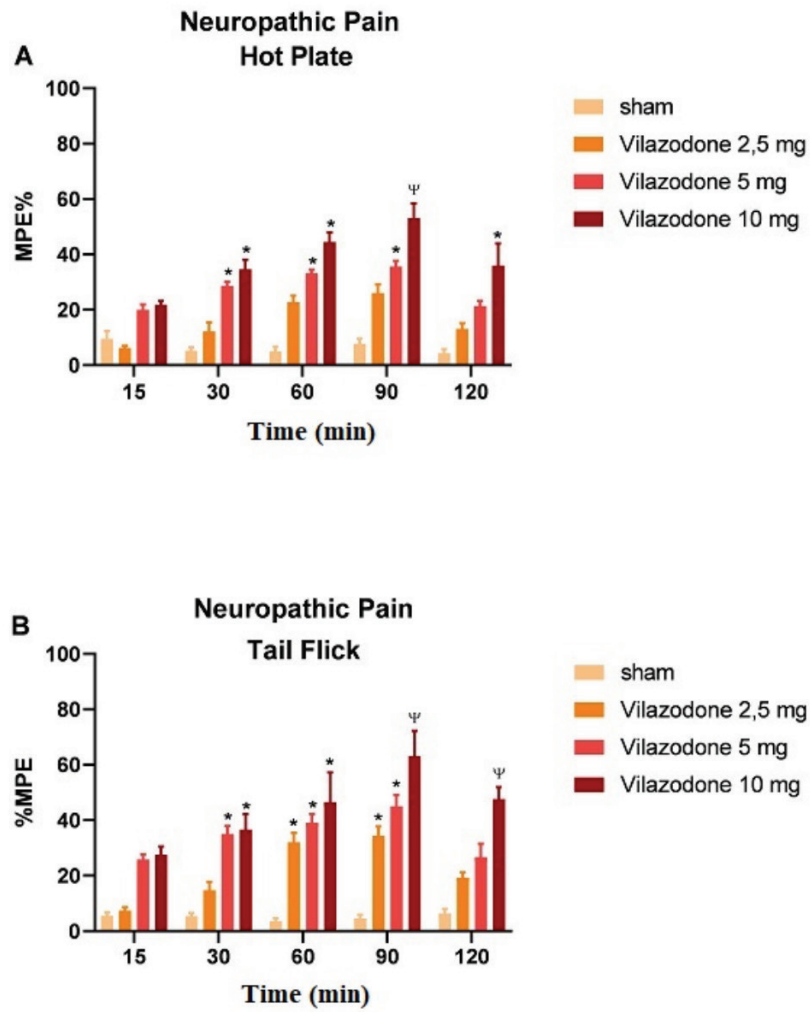

Figure 3. The effect of vilazodone hydrochloride intraperitoneal administration on the neuropathic pain model in the hot plate test $(A)$ and tail flick test (B). This was expressed as a percentage of the maximal possible effect (MPE). Each point represents the mean \pm SEM of \% MPE for 6 rats

${ }^{*} p<0.05$ when the groups were compared to the sham group, $\Psi: p<0.05$ when the groups were compared to the sham and $2.5 \mathrm{mg} / \mathrm{kg}$ dose groups, SEM: Standard error of the mean 
minute points in the hot plate test, while their effectiveness in the tail flick test was noticed from 15 to 90 min compared to dose of $2.5 \mathrm{mg} / \mathrm{kg}$, a statistically significant difference was noticed only with dose at $10 \mathrm{mg} / \mathrm{kg}$ at $60 \mathrm{~min}$ in the hot plate test (Figure 4).

\section{Effects of indatraline hydrochloride on neuropathic pain}

Indatraline hydrochloride was administered intraperitoneally at 3 doses; 2.5, 5, and $10 \mathrm{mg} / \mathrm{kg}$. Maximum MPE\% was observed at 60 min after the drug was administered for all three doses. One-way ANOVA test was applied. The drug was effective at all three doses in both tests. After the first dose $2.5 \mathrm{mg} / \mathrm{kg}$ was administered, the anti-hyperalgesic effect was statistically significant in $60 \mathrm{~min}$ in the hot plate test and from 30 to $90 \mathrm{~min}$ flick test. The second dose at $5 \mathrm{mg} / \mathrm{kg}$ was effective at 30 and 60 mins in the hot plate test and from 15 to $90 \mathrm{~min}$ in the tail flick test. The anti-hyperalgesic effect for the third dose of 10 $\mathrm{mg} / \mathrm{kg}$ from 30 to 90 min was statistically significant compared to the sham group, and at $60 \mathrm{~min}$ the first $2.5 \mathrm{mg} / \mathrm{kg}$ dose in the hot plate test. While in the tail flick test, anti-hyperalgesic effect of $10 \mathrm{mg} / \mathrm{kg}$ dose was clear from 15 to $90 \mathrm{~min}$ compared to the sham group (Figure 5).
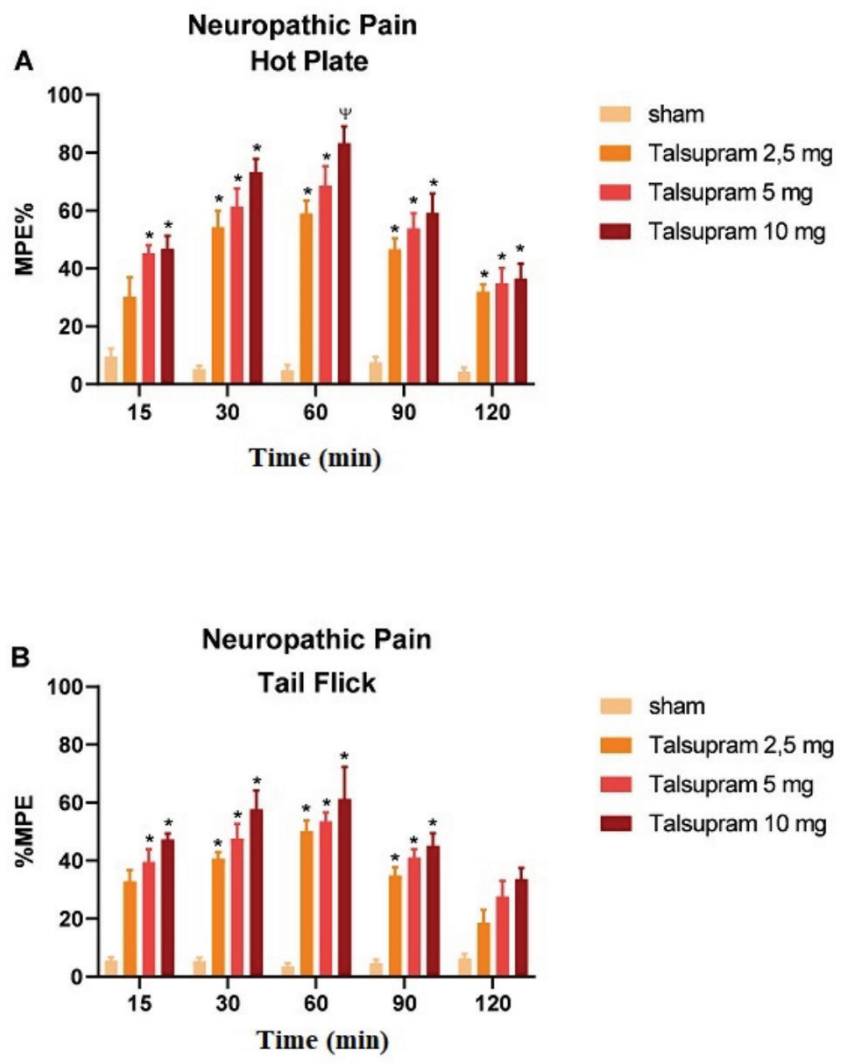

Figure 4. The effect of talsupram hydrochloride intraperitoneal administration on the neuropathic pain model in the hot plate test $(A)$ and tail flick test (B). This was expressed as a percentage of the maximal possible effect (MPE). Each point represents the mean \pm SEM of \% MPE for 6 rats

${ }^{\star} p<0.05$ when the groups were compared to the sham group, $\Psi: p<0.05$ when the groups were compared to the sham and $2.5 \mathrm{mg} / \mathrm{kg}$ dose groups, SEM: Standard error of the mean
Comparison of the anti-hyperalgesic effects of vilazodone hydrochloride, talsupram hydrochloride, and indatraline hydrochloride on neuropathic pain

We used two-way variance analysis followed by Tukey HSD test in this comparison. In hot plate test, MPE\% values obtained from doses of $2.5,5,10 \mathrm{mg} / \mathrm{kg}$ of talsupram hydrochloride dose were significantly higher than values obtained from the same doses of vilazodone hydrochloride and indatraline hydrochloride. Even at lower doses, talsupram was more effective than the other two drugs. MPE\% of talsupram at $2.5 \mathrm{mg} / \mathrm{kg}$ was > vilazodone $5 \mathrm{mg} / \mathrm{kg}$ and indatraline 10 $\mathrm{mg} / \mathrm{kg}$, while at $5 \mathrm{mg} / \mathrm{kg}$, MPE\% was > vilazodone $10 \mathrm{mg} /$ $\mathrm{kg}$ ( $p$ <0.05). Whereas in the tail flick test, MPE\% values obtained from the different doses of talsupram hydrochloride were not statistically different from those of the same doses of vilazodone hydrochloride and indatraline hydrochloride ( $p>0.05$ ), except for MPE\% of $2.5 \mathrm{mg} / \mathrm{kg}$ dose of indatraline hydrochloride, which was higher than that of the same dose of talsupram hydrochloride ( $p<0.05)$. There was a statistically significant difference between the MPE\% values obtained from the same doses of vilazodone hydrochloride and indatraline hydrochloride in favor of the latter in the tail flick test ( $p$ <0.05), whereas no statistically significant difference
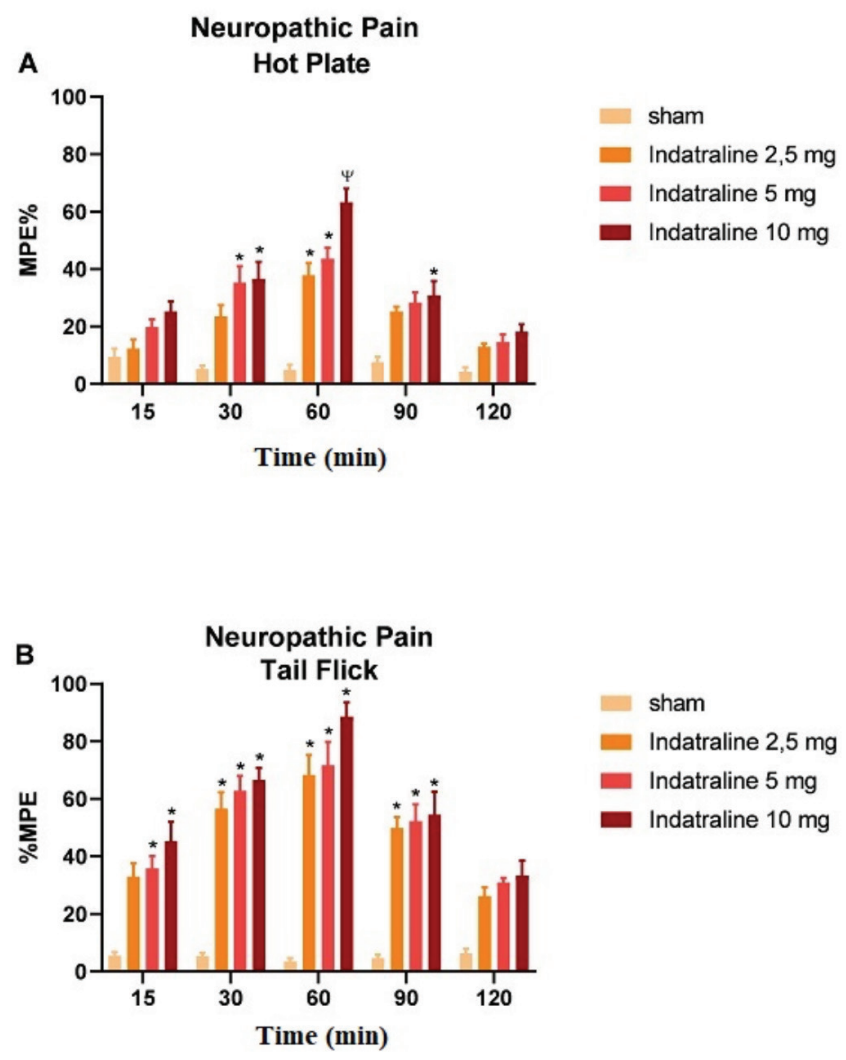

Figure 5. The effect of indatraline hydrochloride intraperitoneal administration on the neuropathic pain model in the hot plate test $(A)$ and tail flick test (B). This was expressed as a percentage of the maximal possible effect (MPE). Each point represents the mean \pm SEM of \% MPE for 6 rats

${ }^{*} p<0.05$ when the groups were compared to the sham group, $\Psi: p<0.05$ when the groups were compared to the sham and $2.5 \mathrm{mg} / \mathrm{kg}$ dose groups, SEM: Standard error of the mean 
was found between them in the hot plate test $(p>0.05)$ (Figure 6).

\section{DISCUSSION}

Neuropathic pain, a pain syndrome caused by a lesion or disease of the somatosensory system, is a main public health issue and becoming a global burden.,19,20 An epidemiological study indicated that the prevalence rate of neuropathic pain is in the range of $6.9 \%$ to $10 \%$ and increases year after year.21,22 Patients with neuropathic pain report significantly lower levels of health-related quality of life. ${ }^{23}$

The high rate of comorbidity between pain and depression ${ }^{24}$ has led to the wide use of antidepressants in chronic pain treatment. Tricyclic antidepressants (TCA), particularly desipramine, amitriptyline, nortriptyline, and imipramine, are the most effective antidepressants in neuropathic pain management. TCAs have effects on various targets. This lack of selectivity is related to their efficacy. For instance, amitriptyline has a local anesthetic effect by blocking voltage-gated sodium channels. ${ }^{25}$ TCAs are effective in many neuropathic conditions. However, these multiple actions of TCAs also contribute to many adverse effects that limit their use, in particular their anticholinergic effects that increase the risk of cardiotoxicity, orthostatic hypotension, mouth dryness, constipation, and urinary retention. To avoid these issues, serotonin-norepinephrine reuptake inhibitors
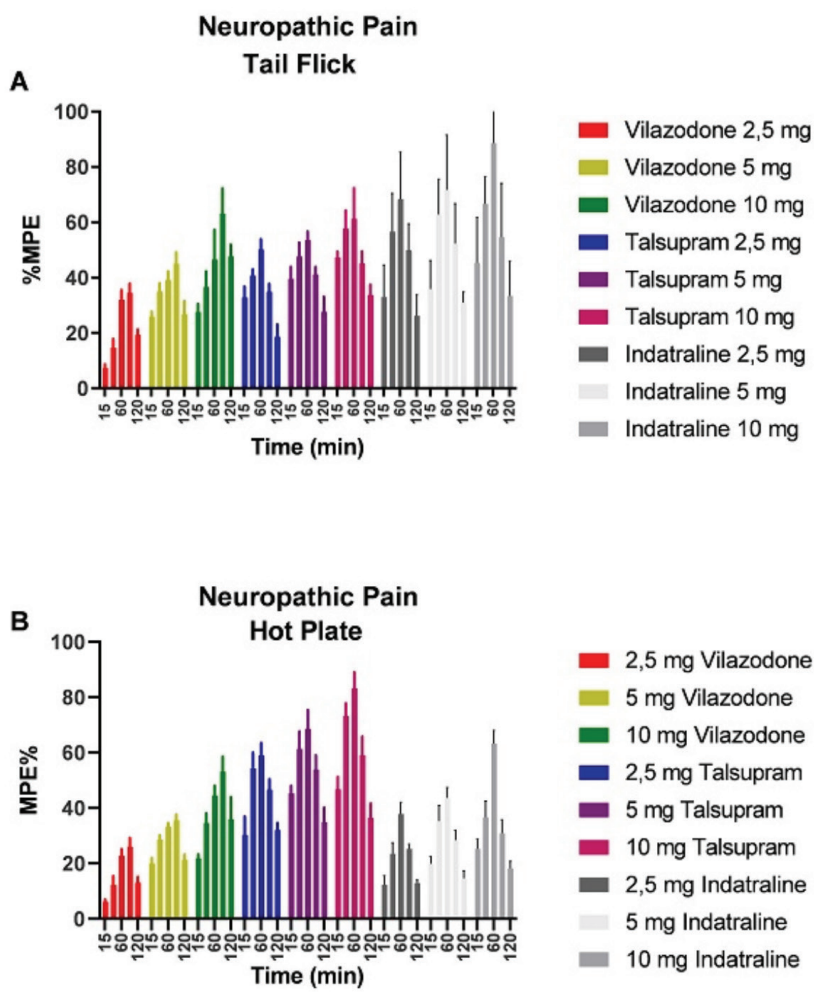

Figure 6. The effect of vilazodone hydrochloride, talsupram hydrochloride and indatraline hydrochloride on the neuropathic pain model (in hot plate and tail flick tests) was expressed as a percentage of the maximal possible effect (MPE). All drugs were administered intraperitoneally. Each point represents the mean of \% MPE for 6 rats.
(SNRI), particularly duloxetine, have been suggested in the management of neuropathic pain. SNRIs, e.g. duloxetine, have shown consistent efficacy in several neuropathic syndromes, including painful polyneuropathy, post-herpetic neuralgia, low back pain, and painful diabetic neuropathy. ${ }^{7}$ Opioids are recommended to be used as second- and thirdline treatments because of their adverse effects. Tramadol and FDA-approved tapentado ${ }^{26}$ are used in second-line treatment, while the strong opioids, oxycodone, and morphine ${ }^{27}$ are used in the third-line treatment. Therefore, there is still a need for more effective drugs with less serious adverse effects for neuropathic pain. In this study, we investigated antihyperalgesic effects of three different antidepressant drugs at different doses in rat models of neuropathic pain using the hot plate method. These drugs have different mechanisms of action; vilazodone hydrochloride is a selective serotonin inhibitor, while talsupram hydrochloride is a selective noradrenaline inhibitor, and it has a high affinity for the noradrenaline transporter, whereas indatraline hydrochloride inhibits transporters for 5-HT, dopamine, and noradrenaline. All the drugs used in the experiment were found to have an anti-hyperalgesic effect compared to the sham group. These results support the evidence for role of noradrenaline, serotonin, and probably dopamine in the analgesic effects of antidepressants on neuropathic pain and corroborate a previous study highlighted that indatraline has analgesic profile in neuropathic mice. ${ }^{28}$ Some preclinical studies on animals have indicated the important roles of noradrenaline and serotonin in the processing of pain. Experimental studies have demonstrated that intrathecal administration of serotonin and norepinephrine receptor agonists inhibits pain behavior. ${ }^{29,30}$ Other data indicate that serotonin agonists such as fenfluramine trigger the neuronal release of substance $P$ and thus pain behavior. ${ }^{31}$ Furthermore, intrathecal administration of serotonin receptor antagonists such as ondansetron inhibits the experimental pain response in rats. ${ }^{32} 5-\mathrm{HT} 1 \mathrm{~A}, 5-\mathrm{HT} 2 \mathrm{~A} / 2 \mathrm{C}$, $5-\mathrm{HT} 3$, and 5-HT7 receptors that highly contribute to the transmission of nociceptive messages are expressed in the dorsal horn of spinal cord. ${ }^{33-36}$ It seems that serotonin both inhibits and enhances pain sensation by various physiological mechanisms, contrary to norepinephrine, which is essentially inhibitor. A review of studies on SSRIs showed inconsistent efficacy for migraine, diabetic neuropathy, and fibromyalgia; however, some studies of SSRI treatment for mixed-chronic pain are positive. ${ }^{37}$

When anti-hyperalgesic effects of three agents were compared to each other, it was found that talsupram hydrochloride was significantly more effective than viazodone hydrochloride and indatraline hydrochloride in the hot plate test. This could be related to the high affinity of talsupram hydrochloride for norepinephrine transporters and the more important role of noradrenaline in the anti-hyperalgesic activity compared to serotonin and dopamine. However, there was no statistically significant difference in the tail flick test.

While the response in the tail flick test is a spinal reflex rather than an indication of pain behavior involving higher brain 
centers, ${ }^{38}$ the response in hot plate test is considered to integrate supraspinal pathways. ${ }^{39}$ Therefore, comparative results suggest that analgesic effect of talsupram hydrochloride is more effective than that of vilazodone hydrochloride and indatraline hydrochloride at the supraspinal level. MPE\% values obtained from indatraline hydrochloride were more than values obtained from vilazodone hydrochloride at the same doses in the tail flick test. This could be due to a greater anti-hyperalgesic effect of the inhibition of the reuptake of noradrenaline, serotonin, and dopamine compared to the inhibition of reuptake of serotonin alone. Although vilazodone hydrochloride is less effective against neuropathic pain than the other drugs, its relatively benign sexual side effect profile may be worth considering because in addition to serotonin reuptake inhibition, it acts as $5-\mathrm{HT}_{1 \mathrm{~A}}$ partial agonist.

\section{CONCLUSION}

In conclusion, our data suggest that the three drugs used in this study are effective analgesics in rat models of neuropathic pain. Inhibition of noradrenaline reuptake represents the cornerstone of analgesic mechanisms of effective antidepressants. Although SSRIs have a more tolerable side effect profile and the SSRI used in our experiment, i.e. vilazodone hydrochloride, was effective in a rat model of neuropathic pain, the evidence to support the use of SSRIs in the clinical management of chronic pain is still not convincing. ${ }^{40}$

\section{ACKNOWLEDGMENTS}

This study was funded by Sivas Cumhuriyet University Scientific Research Project (T-866, Doctoral Thesis Project, CUBAP, Türkiye).

\section{Ethics}

Ethics Committee Approval: All procedures performed in studies involving animals were in accordance with the ethical standards of the institution or practice at which the studies were conducted. Animal experimental procedures were approved by the Animal Ethical Committee at Sivas Cumhuriyet University (Sivas, Türkiye) (approval no: 65202830-050.04.04-284).

Informed Consent: Not human subject research.

\section{Authorship Contributions}

Surgical and Medical Practices: L.H., Concept: B.S., Design: B.S., Data Collection or Processing: L.H., Analysis or Interpretation: Z.J., Literature Search: L.H., Writing: L.H.

Conflict of Interest: No conflict of interest was declared by the authors.

Financial Disclosure: The authors declared that this study received no financial support.

\section{REFERENCES}

1. Jensen TS, Baron R, Haanpää M, Kalso E, Loeser JD, Rice ASC, Treede RD. A new definition of neuropathic pain. Pain. 2011;152:2204-2205.

2. Institute of Medicine (US) Committee on Advancing Pain Research, Care, and Education. Relieving pain in America: a blueprint for transforming prevention, care, education, and research. Washington (DC): National Academies Press (US); 2011

3. Leadley RM, Armstrong N, Lee YC, Allen A, Kleijnen J. Chronic diseases in the European Union: the prevalence and health cost implications of chronic pain. J Pain Palliat Care Pharmacother. 2012;26:310-325.

4. Torrance N, Smith BH, Bennett MI, Lee AJ. The epidemiology of chronic pain of predominantly neuropathic origin. Results from a general population survey. J Pain. 2006;7:281-289.

5. Bouhassira D, Lantéri-Minet M, Attal N, Laurent B, Touboul C. Prevalence of chronic pain with neuropathic characteristics in the general population. Pain. 2008;136:380-387.

6. Henningsen P, Zipfel S, Herzog W. Management of functional somatic syndromes. Lancet. 2007;369:946-955.

7. Finnerup NB, Attal N, Haroutounian S, McNicol E, Baron R, Dworkin RH, Gilron I, Haanpää M, Hansson P, Jensen TS, Kamerman PR, Lund K, Moore A, Raja SN, Rice AS, Rowbotham M, Sena E, Siddall P, Smith BH, Wallace M. Pharmacotherapy for neuropathic pain in adults: a systematic review and meta-analysis. Lancet Neurol. 2015;14:162-173.

8. Dowell D, Haegerich TM, Chou R. CDC Guideline for Prescribing Opioids for Chronic Pain - United States, 2016. MMWR Recomm Rep. 2016;65:149. Erratum in: MMWR Recomm Rep. 2016;65:295.

9. Attal N, Cruccu G, Baron R, Haanpää M, Hansson P, Jensen TS, Nurmikko $T$. EFNS guidelines on the pharmacological treatment of neuropathic pain: 2010 revision. Eur J Neurol. 2010;17:1113-e1188.

10. Finnerup NB, Sindrup SH, Jensen TS. The evidence for pharmacological treatment of neuropathic pain. Pain. 2010;150:573-581.

11. Dworkin RH, O'Connor AB, Backonja M, Farrar JT, Finnerup NB, Jensen TS, Kalso EA, Loeser JD, Miaskowski C, Nurmikko TJ, Portenoy RK, Rice ASC, Stacey BR, Treede RD, Turk DC, Wallace MS. Pharmacologic management of neuropathic pain: evidence-based recommendations. Pain. 2007;132:237-251.

12. Calandre EP, Rico-Villademoros F, Slim M. An update on pharmacotherapy for the treatment of fibromyalgia. Expert Opin Pharmacother. 2015;16:1347-1368.

13. Bee L, Dickenson A. Descending modulation of pain. In: Malcangio M, editor. Synaptic plasticity in pain. New York: Springer Verlag; 2009. pp. 307-335.

14. Seltzer Z, Dubner R, Shir Y. A novel behavioral model of neuropathic pain disorders produced in rats by partial sciatic nerve injury. Pain. 1990;43:205-218.

15. Malmberg AB, Basbaum Al. Partial sciatic nerve injury in the mouse as a model of neuropathic pain: behavioral and neuroanatomical correlates. Pain. 1998; 76:215-222.

16. Kanaan SA, Saadé NE, Haddad JJ, Abdelnoor AM, Atweh SF, Jabbur SJ, Safieh-Garabedian B. Endotoxin-induced local inflammation and hyperalgesia in rats and mice: a new model for inflammatory pain. Pain. 1996;66:373-379.

17. Ramabadran K, Bansinath M, Turndorf H, Puig MM. The hyperalgesic effect of naloxone is attenuated in streptozotocin-diabetic mice. Psychopharmacology (Berl). 1989;97:169-174.

18. Bannon AW, Malmberg AB. Models of nociception: hot-plate, tail-flick, and formalin tests in rodents. Curr Protoc Neurosci. 2007;8:8.9.

19. van Hecke O, Austin SK, Khan RA, Smith BH, Torrance N. Neuropathic pain in the general population: a systematic review of epidemiological studies. Pain. 2014;155:654-662. Erratum in: Pain. 2014;155:1907. 
20. Guevara-López U, Covarrubias-Gómez A, García-Ramos G, HernándezJiménez S; Grupo de Consenso para el Manejo del Dolor Neuropático. Parámetros de práctica para el manejo del dolor neuropático [Practice guidelines for neuropathic pain management]. Rev Invest Clin. 2006;58:126-138.

21. Gilron I, Baron R, Jensen T. Neuropathic pain: principles of diagnosis and treatment. Mayo Clin Proc. 2015;90:532-545.

22. Mayoral V, Pérez-Hernández C, Muro I, Leal A, Villoria J, Esquivias A. Diagnostic accuracy of an identification tool for localized neuropathic pain based on the IASP criteria. Curr Med Res Opin. 2018;34:1465-1473.

23. Meyer-Rosberg K, Burckhardt CS, Huizar K, Kvarnström A, Nordfors LO, Kristofferson A. A comparison of the SF-36 and Nottingham Health Profile in patients with chronic neuropathic pain. Eur J Pain. 2001;5:391403.

24. Fishbain DA, Cutler R, Rosomoff HL, Rosomoff RS. Chronic painassociated depression: antecedent or consequence of chronic pain? A review. Clin J Pain. 1997;13:116-137.

25. Sudoh Y, Cahoon EE, Gerner P, Wang GK. Tricyclic antidepressants as long-acting local anesthetics. Pain. 2003;103:49-55.

26. Vadivelu N, Kai A, Maslin B, Kodumudi G, Legler A, Berger JM. Tapentadol extended release in the management of peripheral diabetic neuropathic pain. Ther Clin Risk Manag. 2015;11:95-105.

27. Attal N. Pharmacological treatments of neuropathic pain: the latest recommendations. Rev Neurol (Paris). 2019;175:46-50.

28. Hache G, Guiard BP, Nguyen TH, Quesseveur G, Gardier AM, Peters D, Munro G, Coudoré F. Antinociceptive activity of the new triple reuptake inhibitor NS18283 in a mouse model of chemotherapy-induced neuropathic pain. Eur J Pain. 2015;19:322-333.

29. Fishbain DA, Detke MJ, Wernicke J, Chappell AS, Kajdasz DK. The relationship between antidepressant and analgesic responses: findings from six placebo-controlled trials assessing the efficacy of duloxetine in patients with major depressive disorder. Curr Med Res Opin. 2008;24:3105-3115.

30. Gendreau RM, Thorn MD, Gendreau JF, Kranzler JD, Ribeiro S, Gracely RH, Williams DA, Mease PJ, McLean SA, Clauw DJ. Efficacy of milnacipran in patients with fibromyalgia. J Rheumatol. 2005;32:19751985.

31. Goldenberg DL, Clauw DJ, Palmer RH, Mease P, Chen W, Gendreau RM. Durability of therapeutic response to milnacipran treatment for fibromyalgia. Results of a randomized, double-blind, monotherapy 6-month extension study. Pain Med. 2010;11:180-194.

32. Gray AM, Pache DM, Sewell RD. Do alpha2-adrenoceptors play an integral role in the antinociceptive mechanism of action of antidepressant compounds? Eur J Pharmacol. 1999;378:161-168.

33. Bardin L. The complex role of serotonin and 5-HT receptors in chronic pain. Behav Pharmacol. 2011;22:390-404.

34. Viguier F, Michot B, Hamon M, Bourgoin S. Multiple roles of serotonin in pain control mechanisms-implications of 5- $\mathrm{HT}_{7}$ and other 5- $\mathrm{HT}$ receptor types. Eur J Pharmacol. 2013;716:8-16.

35. Yoshimura M, Furue $H$. Mechanisms for the anti-nociceptive actions of the descending noradrenergic and serotonergic systems in the spinal cord. J Pharmacol Sci. 2006;101:107-117.

36. Millan MJ. Descending control of pain. Prog Neurobiol. 2002;66:355474.

37. Jung AC, Staiger T, Sullivan M. The efficacy of selective serotonin reuptake inhibitors for the management of chronic pain. J Gen Intern Med. 1997;12:384-389.

38. Irwin S, Houde RW, Bennett DR, Hendershot LC, Seevers MH. The effects of morphine methadone and meperidine on some reflex responses of spinal animals to nociceptive stimulation. J Pharmacol Exp Ther. 1951;101:132-143.

39. Giglio CA, Defino HL, da-Silva CA, de-Souza AS, Del Bel EA. Behavioral and physiological methods for early quantitative assessment of spinal cord injury and prognosis in rats. Braz J Med Biol Res. 2006;39:16131623.

40. Smith AJ. The analgesic effects of selective serotonin reuptake inhibitors. J Psychopharmacol. 1998;12:407-413. 